\title{
Didactic Engineering in the Study of the Sense of Variation of Functions: Preliminary Analysis
}

\author{
Noé Oswaldo Cabañas-Ramírez ${ }^{1 *}$, Edgardo Locia-Espinoza ${ }^{1}$, Armando Morales-Carballo ${ }^{1}$ \\ ${ }^{1}$ Autonomous University of Guerrero, MÉXICO \\ *CORRESPONDENCE: $\triangle$ noe_ocr@hotmail.com
}

\begin{abstract}
This paper shows the results of the epistemological and didactical analysis of the sense of variation of functions. Specifically, on the conceptions of growth and decay in a function that underlie the demonstrations of the theorem that links the sign of $f^{\prime}$ with the sense of variation of $f$. The epistemological approach covered the years 1795 to 1912. It was identified that the conceptions of Fourier, Lagrange and Cauchy about growth and decay differ from the conception in the formal current definition; however, the posed procedures and definitions provide elements that foster reconstruction processes of the definitions and properties of increasing and decreasing functions. It is important to highlight that the current definition of growth and decay has a solid foundation on the definition made by Osgood in 1912. The didactical analysis identified that the current text books inherit some of the limitations and inconsistencies of the definitions found on the epistemological approach. The conflicting issues enhance the starting point for the development of a didactic engineering for the treatment of the sense of variation of a function at a preuniversity level.
\end{abstract}

Keywords: function, sense of variation, growth, decay, didactical engineering

\section{INTRODUCTION}

Analysis of functions is a required content in the curricula and programs of upper secondary levels, at least in Mexico. Analysis of functions is understood as the study of the sense of variation, growth and decay in a function, intervals of concavity and convexity, inflection points, vertical, horizontal and oblique asymptotes and identification of maximum and minimum values (Leithold, 1992; Swokowski, 1982). It is an integrative concept where the main concepts of differential calculus are used and converge; it encourages the students' mathematical reasoning maturity to understand and apply the theorems and results built in these concepts.

Despite of the importance of this content, several works focused on the study of the teaching and learning processes of calculus make evident the difficulties in understanding the basic concepts of calculus among students in middle and high school levels of education, such as the concept of function, growth and decay, maximums and minimums, and others (Castillo, 2009; Cuevas \& Delgado, 2016; Delgado, 2013; Díaz, 2009; Pineda, 2013; Reséndiz, 2006; Rubí, Moreno, Pou, \& Jordán, 2010; Ruiz, Hernández, \& Gutiérrez, 2015; Salinas \& Alanís, 2009; Zúñiga, 2009).

This issue gave rise to investigations from different theoretical and methodological referents to study the sense of variation of a function (Díaz, 2009; Engler, Vrancken, Gregorini, Müller, Hecklein \& Henzenn, 2008; Rey Cabrera, 2016; Zúñiga, 2009). The results of these investigations highlight the existence of difficulties in the understanding and treatment of this content of teachers and students. For example, Russo (2016),

Article History: Received 19 August $2019 \bullet$ Revised 23 October $2019 \bullet$ Accepted 23 October 2019

(C) $\mathbf{2 0 2 0}$ by the authors; licensee Modestum Ltd., UK. Open Access terms of the Creative Commons Attribution 4.0 International License (http://creativecommons.org/licenses/by/4.0/) apply. The license permits unrestricted use, distribution, and reproduction in any medium, on the condition that users give exact credit to the original author(s) and the source, provide a link to the Creative Commons license, and indicate if they made any changes. 
Sánchez-Matamoros, García and Llinares (2008) document the difficulties in understanding, building and interpreting the basic concepts of calculus faced by students, such as the concept of function, growth and decay and maximums and minimums. Engler and Vrancken (2002) observed students' difficulties to solve problems that involved the fundamental concepts of calculus: first and second derivative and their relationships with the concepts of growth and decay in a function, concavity and convexity and maximum, minimum and inflection points. These issues are identified in the students for two reasons; on the one hand they have not built a proper meaning in the first courses of calculus, as a consequence of the diverse previous conceptions of the students that may have contradictory aspects and are very resistant to change; on the other hand, there is a trend in traditional teaching to overestimate algorithmization and analytical methods over the development of abilities concerning mathematical thinking.

Besides, a study of Valero (2003) found that upper secondary school students, who have already addressed the topic of analysis of functions, associated increasing functions with positive functions and decreasing functions with negative functions. The researcher in this study identified the following alternative conceptions about the sense of variation of functions: the conception that considers that a function with a positive image is necessarily increasing; the conception that considers that a function has a negative image only when it is decreasing; considering the zeros of a function as stabilization points; the conception that a function has a positive image only when its abscissae and ordinate are positive; the conception that a function has a negative image only when its abscissae and ordinate are negative; the conception that consists in considering intervals as if they were points; the conceptions in which the function does not grow or decrease at $x=0$; a function is increasing if its graph goes up with no coordination among the changes in the abscissae and the changes in the ordinates; a function is decreasing if its graph goes down. These conceptions will be considered in the productions of the students in subsequent paragraphs.

As identified before, teachers and students have difficulties in understanding calculus, specifically the sense of variation of a function. These situations draw our attention to the next problem: How can the teaching and learning processes of the sense of variation of a function be promoted in a pre-university educational level?

\section{THEORETICAL FOUNDATION}

The aim of this work is to contribute to the elaboration and implementation of a didactic engineering for the treatment of the sense of variation of a function. Teacher, students and mathematical content are the main actors in this activity. It is also assumed the possibility of students building knowledge from adaptations of the environment in which the knowledge is built.

Brousseau (1978) proposes that the design of situations that include a set of activities promoting the fictitious emergence of knowledge is a proper setting for students' learning. These activities will turn the class into a micro-scientific community within which knowledge (concepts and results) is built as a necessary and optimal tool to overcome the epistemological, didactical and cognitive obstacles of the mathematics content in play, giving place to different a-didactic phases (in the production of knowledge, these are modeled activities conceived for the independent interaction between student and environment, without the teacher intervention) and didactic phases (action, formulation, validation and institutionalization) which are fundamental phases in the construction of knowledge according to the theory. Specifically, these situations are treated as a consequence of the preliminary analysis of the central object of study described in this work. In these micro-scientific communities, students make individual or team proposals to overcome the obstacles, submit them to discussion with their peers, validate or question them through counterexamples, establishing a dialectic between validation and refutation similar to the one described by Lakatos (1976).

Lakatos (1976) emphasizes that, in many cases, the first ideas of the proof of some results contained implicit elements supported by evidence or used not-completely defined notions, hiding some mistakes or contradictions. Suggesting a counterexample that evidences a contradiction, may lead to question the proof looking for implicit elements that give place to that counterexample, improving conjectures, demonstrations or definitions of the notions involved until they are rejected or placed in the proper place of the theoretical axiomatic building. In this sense, Brousseau established that situations involving the fictitious emergence of knowledge must be designed in such a way that students explore a similar path to the one mathematicians take (process described by Lakatos). In this path, mistakes and the existence of contradictions in arguments (evidenced by the counterexamples) are not seen as eventualities but acquire a positive status promoting that students examine their arguments, diagnose problems and overcome them, give meaning to the contents, procedures or cognitive processes. This may lead to new knowledge and ideas. 
On the other hand, García and Morales (2013), Hernández, Locia, Morales and Sigarreta (2019), Klymchuk (2012), Morales, Locia, Ramírez, Sigarreta and Mederos (2018), Zazkis and Chernoff (2008) concur that the formulation of conjectures and the use of counterexamples stimulates students reasoning of the how and why of the processes followed to reach the conclusions and reduce algorithmic and rote learning procedures so that it is necessary to introduce proper settings that promote the achievement of these pedagogical virtues of counterexamples.

\section{METHODOLOGICAL FOUNDATION}

Didactic engineering (DE) is the methodology used in this investigation, because it assigns a specific function to the research according to the four phases that conform it: phase 1 of preliminary analysis; phase 2 of conception and an a priori analysis; phase 3 of experimentation; and phase 4 of an a posteriori analysis and assessment. The fundamental characteristic of the DE is the confrontation between the a priori and the a posteriori analysis of the productions of the implementation of the tasks in the classroom.

This paper presents the preliminary analysis which includes an epistemological, didactical and cognitive study of the object of study, the sense of variation of functions of a real variable. In this context, the focus is the analysis of the historic-epistemological development of the different conceptions witnessed, of the knowledge involved in the study of the sense of variation of the functions and the differences and similarities between the knowledge in construction, the scientific knowledge and the taught knowledge. The analysis of the traditional teaching and its effects considered the role of textbooks through the characterizations or communications that the teacher obtained from them. From the analysis of students' conceptions, information is obtained referring to the application and correct use of the properties of concepts, theorems and definitions.

\section{METHOD}

The conceptions of growth in a function underlying the demonstrations of the theorem that link the sign of $f$ ' with the sense of variation of $f$ given by Lagrange and Cauchy are considered in the epistemological analysis. The evolution of the notion of increasing function, from the works of Fourier in 1795, until its formalization in the current definition given by Osgood in 1912, is monitored from original sources.

The main textbooks on these notions used in upper-secondary level and the first years of university are considered in the didactical analysis; it is assumed that these books are a fundamental part in the teaching and learning processes. Three aspects organized the analysis of texts: (a) analysis of the treatment of definitions, (b) analysis of the main theorems and results, and (c) analysis of the effective procedures.

For the cognitive analysis, a tool with written activities and direct questions was applied to fourteen students in the first semester of the Bachelor's Degree in Mathematics. The productions of the students about their representations, justifications and built meanings in their prior level of education were analyzed.

\section{HISTORIC-EPISTEMOLOGICAL, DIDACTICAL AND COGNITIVE ELEMENTS OF THE NOTION OF SENSE OF VARIATION: DISCUSSION AND ANALYSIS}

\section{Definitions}

At the end of the 18th century the first elements of the formalization of the Calculus are identified; therefore, it was decided to study the definitions of the sense of variation of functions in the period of time from 1795 to 1912. In this period, the pure geometric studies of Fourier, the implicit definitions of Lagrange and Cauchy, the first explicit definition evoked by Ampère and the first formal definition about the sense of variation expressed by Osgood in 1912 were identified.

\section{Fourier}

One of the first evidences of the relationship between the sign of the derivative and the sense of variation of a function was found in the works of Joseph Fourier by the end of 1795 . The search for maximums and minimums by purely geometric considerations allowed him to identify the necessary condition to obtain an extreme point, as described here (see Figure 1): the curve of a function and "the curve of the slopes" namely, the derivative function, are reproduced in the same figure (from the lower figure to the point $\mathrm{M}$ in the curve of a function, he sets $M R=1$; then $S R$ is the tangent of the angle SMR that he draws in $P$ to obtain a point that belongs to the slope curve). In this way, he observed that an extreme point of the slope curve corresponds with 


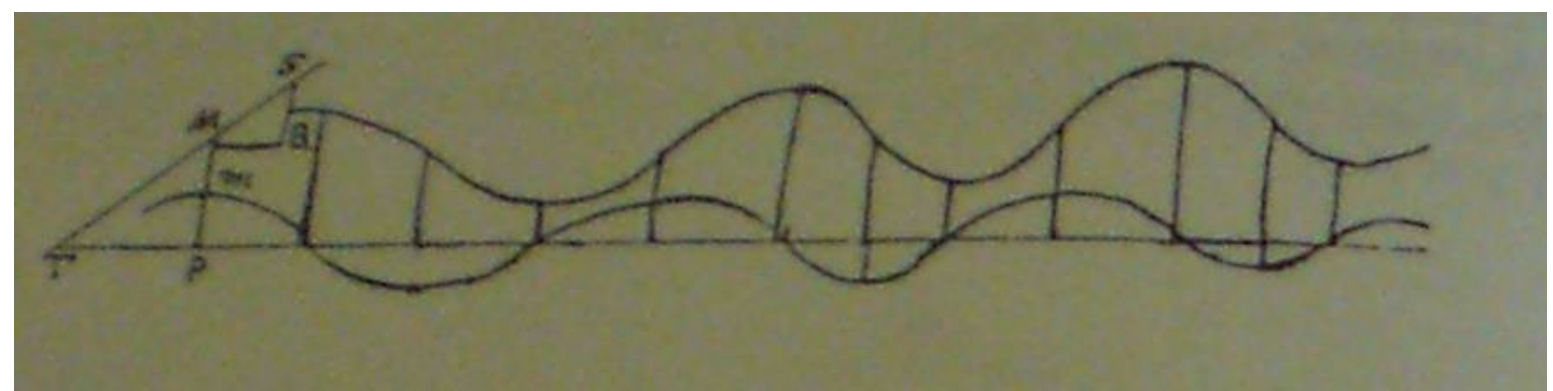

Figure 1. Geometric illustration of the curve of a function and "the curve of the slopes"

an inflection point in the curve of a function. He immediately reports the "second slope curve (curve that could be denominated second curve)" to observe that if the first curve is convex, the second one has increasing ordinates and the ordinates of the third one are positive and if the first curve is concave, the ordinates of the second one are decreasing and the ordinates of the third are negative (Renaud, 2017).

After this, the search for new ways to study extreme points continued; the search in "purely analytical ways" using the theorem of Taylor was among them,

The review of the original texts of Lagrange and Cauchy revealed lemmas and theorems with implicit signs of conceptions of the definition of an increasing function, even when they never presented an explicit formal definition of increasing/decreasing function.

\section{Lagrange and Cauchy}

The proofs given by Lagrange and Cauchy (later analyzed) indicate that they have implicit conceptions of what an increasing function is (they never gave a definition) but these conceptions do not match exactly. The conception of Lagrange is closer to what we actually find in higher education textbooks because it can be deduced that the difference $f(b)-f(a)$ is positive with the hypothesis of the positivity of the derivative and the inequality $b>a$.

On the other hand, the implicit definition of an increasing function of Cauchy can be formulated in the next way: a function $f$ defined in an interval $I$ is an increasing function if, for any element $a$ of $I$, there is a neighborhood $V(a)$ such that for any $x$ in $V(a)$, the order between $f(a)$ and $f(x)$ is the same as between $a$ and $x$. The definition of Lagrange is global and punctual and refers to two given points (arbitrarily and independently); the local properties remain in a neighborhood of each of the arbitrary points in the definition of Cauchy. It can be proved without difficulties that both definitions are equivalent from a mathematical point of view. However, according to Chorlay (2007), these definitions are significantly different from the epistemological point of view (in drawing attention to the differences between local and global properties) and also from the cognitive point of view.

\section{Ampère}

The first implicit "definition" of an increasing function is found in Ampère (1824) and is expressed in the following terms: A continuous function is increasing in the interval between two values of the independent variable if it increases for larger values of this variable and, consequently, it decreases for smaller values of the same variable; it is said that the function is decreasing if its values are decreasing as long as the independent variable increases, and it increases to the extent that such variable decreases. It is evident that if $y$ and $Y$ represent the values of the function of one independent variable, corresponding to the two values $x$ and $X$ of this variable, the fraction $\frac{Y-y}{X-x}$, named as the quotient of the differences of the variable and its function, will always be positive for increasing functions, and negative for decreasing functions. ${ }^{1}$

\footnotetext{
${ }^{1}$ On dit qu'une function continue est croissante dans l'intervalle de deux valeurs de la variable indépendante, quand elle augmente à mesure qu'on donne à cette variable des valeurs de plus en plus grandes, et qu'elle irait par conséquent en diminuant, si l'on donnait à la même variable des valeurs de plus en plus petites: on dit que la fonction est décroissante quand elle va en diminuant à mesure que la variable indépendante augmente, et en augmentant à mesure que cette dernière diminue. Il est évident que si $y$ et $Y$ représentent deux valuers d' une fonction d'une seule variable indépendante, correspondantes à deux valeurs $x$ et $X$ de cette variable, la fraction $\frac{Y-y}{X-x}$, que l'on nomme le rapport des différences de la variable et de sa fonction, sera toujours positive quand la function est croissante, et négative quand elle est décroissante.
} 
More than a definition, this is an intuitive description of the variation of how two quantities change, one of which depends on the other (if one increases, the other one does as well, when referring to increasing function; or when one increases, the other decreases when referring to decreasing function). Chorlay (2007) named this "the narrative style" which is prior to formalization.

\section{Osgood}

It is amazing that the notion of the sense of variation of a function was not defined, as actually known, until 1912 when W.F. Osgood wrote for the first time in the book Lehrbuch der funktionentheorie (Textbook of Function Theory): A function is called monotonous if it has the following behavior: Let $x_{1}$ and $x_{2}$ be two arbitrary points in the domain of definition such that $x_{1}<x_{2}$. Then, without exception, it should always be $f\left(x_{1}\right) \leq f\left(x_{2}\right)$, or always $f\left(x_{1}\right) \geq f\left(x_{2}\right)$, (Osgood, 1912, p.27) ${ }^{2}$

It is important to highlight that this definition did not appear in the previous edition of this book in 1907. The definition appears in the edition from 1912 immediately after the demonstration of the theorem of finite increments, that was made in the same way as today, and after expressing the generalization of the theorem as the development of a sum of powers and what remains as what is actually known as Lagrange remainder.

Concerning the results of the sense of variation of the functions of real variable and the existence of maximums and minimums, the actual definitions are given in terms of inequalities. Furthermore, this is the definition that appears in the actual mathematical textbooks and was the culmination of the analysis of functions taking the works of Fourier, Lagrange, Cauchy, Ampère and Osgood as reference.

In this way, the notions of growth and decay of a function of real variable were evoked in a purely narrative way (Chorlay, 2007) for a long time; it was made explicit for the first time in the works of Ampère but only found a purely punctual formulation until Osgood, acquiring at the same time the status of a real definition. The conception that underlies this definition is the transformation of an ordered set into another ordered set in such a way that the order is preserved if the function is increasing or is inverted if the function is decreasing.

\section{Theorems}

\section{Rolle}

Rolle's theorem was published in 1690 in the book Traité d'Algèbre (Treatise on Algebra) with the title of "Method of Cascades". This method consists in submitting an equation to a process of "preparation"; in this way, given a polynomial equation $f(x)=0$, Rolle specified a multiplication of the function $f(x)$ by a sequence and equates to 0 , and obtained what he named a cascade. After multiplying each term of $f(x)$ with the corresponding term of the sequence, the resulting expression is divided by $x$ and equated the quotient to zero. Subsequent cascades are obtained by the reiteration of this process until the first cascade of the form $a x+b=$ 0 is achieved. From this point, Rolle considered the following cascades and obtained the upper and lower bounds ensuring that those intervals contain one (and only one) root. Eventually, the theorem was proved in a book about Algebra and Geometry named Démonstration d'une méthode pour résoudre les égalités de tous les degrés, suivi de deux autres méthodes, dont la première donne les moyens de résoudre ces mêmes égalités par la géométrie, et la seconde pur résoudre plusieurs questions de Diophante qui n'ont point été résolues (Demonstration of a method to solve equations of all degrees, followed by two other methods, the first of which gives the means to solve these same equations by geometry, and the second to solve several Diophantine problems that have not been resolved) in 1691, that contributes to the solution of the problem of the existence of the roots of equations of any degree. It is important to make clear that the first proofs of the theorem that associates the sense of variation of a function with the sign of its derivative did not use this theorem.

The origin of the transition of this theorem from Algebra to Mathematical Analysis is in the genius of Euler; he expressed this theorem in terms of the language of Calculus for the first time in his work Institutiones calculi differentialis (Foundations of Differential Calculus) (Suárez, 2011; Suso and Velasco, 2013). Since one of the cases in which two given real roots of the equation $z=0$ is when the function $z$ reaches a minimum or maximum value, it can be deduced that if the equation $z=0$ has two real roots, then the equation $\frac{d z}{d x}=0$ necessarily has a real root. Similarly, if the equation $z=0$ has three real roots, then the equation $\frac{d z}{d x}=0$

\footnotetext{
2 Eine Funktion heißt monoton, wenn sie, wie folgt, beschaffen ist. Seien $x_{1}$ y $x_{2}$ irgen zwei Punkte des Definitions bereichs und sei $x_{1}<x_{2}$. Dann soll ohne Ausnahme $f\left(x_{1}\right) \leq f\left(x_{2}\right)$ sein oder aber es soll stets $f\left(x_{1}\right) \geq f\left(x_{2}\right)$ sein.
} 
undoubtedly has two real roots. And, in general, if the equation $z=0$ has $m$ real roots, then the equation $\frac{d z}{d x}=$ 0 necessarily has at least (m-1) roots (Euler, 1755) ${ }^{3}$.

Euler's presentation of Rolle's theorem is quite different from the ones of their predecessors, because for the first time, it is presented with the support of calculus and without the method of cascades even when the polynomial equations are still in the context. Eventually, Lagrange and Cauchy obtained their mean value theorems applying Rolle's theorem to different types of functions.

\title{
Lagrange
}

For its part, as noted in the title and in the preface of his work, Theory of analytic functions that contain the foundations of differential calculus deprived of any consideration of infinitely small or evanescent, limits or fluxions and reduced to the algebraic analysis of finite quantities, (Théorie des fonctions analytiques, contenant les principes du calcul différentiel, d'egagés de toute considération d'infiniment petits, d'evanouissans, de limites et de fluxions, et réduite àl'analyse algébrique des quantités finies), Lagrange (1797), rejected the notions of infinitely small quantities or evanescent quantities, the notions of limit and fluxions as the starting point for a systematic and rigorous exposition of the mathematical analysis, placing as a fundamental notion the development of a function in a series of the form: " $f(x+i)=f(x)+p i+q i^{2}+r i^{3}+$ $\& c^{\prime \prime}$, with $p, q, r, \ldots$ also functions of $x$, as the fundamental notion. Lagrange defines the derivative of a function $f(x)$, avoiding the notion of limit, as the coefficient of the factor $i$ in this development, namely as $f^{\prime}(x)=p$. The derivatives of superior orders are defined in a similar way.

Lagrange states and proves the following lemma in this work:

If a prime function of $z$ like $f^{\prime} z$ is always positive for any value of $z$, from $z=a$ up to $z=b$ supposing that $b$ is $>a$, the difference of the primite functions corresponds to these two values of $z$, i.e., $f b-f a$, it will necessarily be a positive quantity. (p. 45) ${ }^{4}$

We will only mention some aspects of the demonstration in view of the goal and orientation of this work: Lagrange avoids the use of the notion of limit and uses another "basic principle" stated and proved at the beginning of his work, this should be seen [...] as one of the fundamental principles of the theory (p.12): in the serial development of a function, $i$ can always be taken sufficiently small so that any term is greater than the sum of the terms that follow it.

In the ninth lesson of Leçons sur le calcul des fonctions (Lessons on the calculus of functions) (Lagrange, 1806) entitled On how to obtain the limits of the development of a function when there is only a finite number of terms, with the same goal of the previous lemma, Lagrange it was proposed to find bounds for the remainder of the polynomial development of order n-1, namely, for an n-times derivable function; which corresponds in actual terms to the inequality of Taylor-Lagrange. For this purpose, he established a modification to the previos lemma, and expressed, would be useful in repeatedly. This principle is stated in the following terms:

\begin{abstract}
A function that vanishes when the variable does will necessarily have, insofar as the variable increases positively, some finite values having the same sign as those of its derivative function, or the opposite sign, if the variable increases negatively, insofar as the values of the derivative function will maintain the same sign and do not become infinite. $(p .89)^{5}$
\end{abstract}

\footnotetext{
${ }^{3}$ Quia inter binas quasuis aequationis $z=0$ radices reales datur vnus cafus, quo function $z$ fit maximum vel minimum; fequitur fi aequatio $z=0$ duas habeat radices reales, tum aequationem $\frac{d z}{d x}=0$ neceffario vnam radicem habituram effe realem. Pariter fi aequatio $z=0$ tres habeat radices reales, tum aequatio $\frac{d z}{d x}=0$ certo duas habebit radices reales. Atque generatim fi aequatio $z=0$ habeat $m$ radices reales, neceffe eft vt aequationis $\frac{d z}{d x}=0$ ad minimun fint $(m-1)$ radices reales. ${ }^{4} \mathrm{Si}$ une fonction prime de $z$ telle que $f$ 'z est toujours positive pour toutes les valeurs de $z$, depuis $z=a$ jusqu'à $z=b, b$ étant $>a$, la différence des fonctions primitives qui répondent à ces deux valeurs de $z$, savoir, $f b-f a$, será nécessairement une quantité positive.

${ }^{5}$ Une fonction qui est nulle lorsque la variable est nulle aura necessairement, pendant que la variable croitra positivement, des valeurs finies et de meme signe que celles de sa fonction derivee, ou de signe oppose si la variable croit negativement, tant que les valeurs de la fonction derivee conserveront le meme signe et ne deviendront pas infinies.
} 
The demonstration of Lagrange is based on the following claim: It is clear that in the expression

$$
f(x+i)=f x+i\left(f^{\prime} x+V\right)
$$

where $V$ is a function of $x$ and $i$ and vanishes for $i=0$, increasing imperceptibly $i$ starting from zero, the value of $V$ will increase imperceptibly from zero, whether it is positive or negative, up to certain point. We read here a continuous function and assume, in actual terms, that it is piecewise monotone even when the notion of continuous function does not appear.

Let us note that even when he did not wish to use the definition of derivative from the notion of limit in this demonstration, his arguments included this idea in phrases like one can always give $i$ a value such that the corresponding value of $V$, apart from the sign, is smaller than a given quantity, and for smaller values of $i$ the value of $V$ is also smaller. We can even note the existence of an implicit notion of increasing function in the statement or mentioned theorem that is similar to the one we use now with inequalities.

An interesting situation of these results is that the goal of the proof of this theorem was not the analysis of the sense of variation of functions, but with these theorems, Lagrange proved the theorem that is now known as the Theorem of finite increments (or Lagrange's theorem). Nowadays, this theorem is the base to prove the theorem that links the sign of the derivative with the sense of variation of a function.

\section{Cauchy}

On the other hand, unlike Lagrange, Cauchy based his works of rigorization of the analysis in the notion of limit. In the sixth lesson of his book Résumé des leçons données à l'Ecole Royale Polytechnique sur le Calcul Infinitésimal (Summary of lessons given at the Royal Polytechnic School on Infinitesimal Calculus), Cauchy (1823) focused on the presentation of problems whose solutions required the derivative of functions of one single variable. He defined derivative as a limit and posed the first problem associated with the theorem that links the sign of the derivative with the sense of variation of a function; he established and solved it in the following terms:

Problem. Assuming that the function $y=f(x)$ is continuos relative to $x$ in the neighborhood of a specific value $x=x_{0}$, one asks whether the function increases or decreases from this value, as the variable itself is made to increase or decrease. (p. 21)6

As we know, this theorem is valid, so no counterexample can be the opposite. However, the proof given by Cauchy is not the one we now know and use in the courses of analysis at the university level.

We can sum up the proof given by Cauchy in the following way: first, a step from the infinitesimal (positivity of $f^{\prime}\left(x_{0}\right)$ ) to the local (the positivity of $\frac{\Delta y}{\Delta x}$ can be deduced from the positivity of $f^{\prime}\left(x_{0}\right)$ for really small values of $\Delta x$ ). Then he goes from the local to the global in an interval. We now know that in the step from the infinitesimal to the local, it is not possible to deduce the increment of $f$ in a neighborhood of $x_{0}$ from the fact that $f^{\prime}\left(x_{0}\right)$ is positive (Chorlay, 2014). This fact is evident with the next counterexample:

$$
f(x)=\left\{\begin{array}{cc}
\frac{1}{2} x+x^{2} \sin \frac{1}{x}, & \text { if } x \neq 0 \\
0, & \text { if } x=0
\end{array}\right.
$$

In fact, it can be shown that this well-defined, continuous and derivable function in all $\mathbb{R}$ satisfies that $f^{\prime}(0)=\frac{1}{2}>0$; however, it is not increasing in any neighborhood of 0 , according to the actual definition of an increasing function.

The "mistake" underlying the proof of Cauchy is the conception of growth that he seems to have and that can be perceived in the last lines of his demonstration: "Let us assume that the function $y=f(x)$ remains continuous between two given limits $x=x_{0}$ and $x=X$. If variable $x$ is made to increase by imperceptible degrees from the first limit to the second one, function $y$ shall increase every time its derivative, while being finite, has a positive value" (Chorlay, 2007, p. 34). This is the same situation presented in the theorem proved by Lagrange.

\footnotetext{
${ }^{6}$ Problème. La function $y=f(x)$ étant suppose continue par rapport à $x$ dans le voisonage de la valeur particulière $x=x_{0}$, on demande si, à partir de cette valeur, la function croît ou diminue, tandis que l'on fait croître or diminuer la variable ellemême.
} 


\section{DEFINITIONS ABOUT THE SENSE OF VARIATION OF A FUNCTION IN TEXTBOOKS}

The following books were reviewed: Aguilar, Bravo, Gallegos, Cerón, and Reyes, 2010; Apostol, 1967; Arteaga and Espinoza, 2014; Ayres, 1971; Ayres and Mendelson, 2001; Contreras, 2014; Cuéllar, 2007; Cuevas, Sánchez and Aparicio, 2012; Garza, 2015; Granville, 2007; Ibañez and García, 2007; Leithold, 1992; Ortiz, 2009; Ortiz, Ortiz and Ortiz, 2011; Piskunov, 2008; Sántalo and Carbonell, 2011; Silva, 2014; Stewart, 2007; Swokowski, 1982; Valdés, 1983.

Four definitions of an increasing function were identified in these texts:

Definition 1: A function $f$ is increasing in a set $S$, if for any two points $x_{1}$ and $x_{2}$ of $S, x_{1}<x_{2}$ implies that $f\left(x_{1}\right) \leq f\left(x_{2}\right)$.

Definition 2: A function $f$ is said to be increasing, when a greater value of the argument $x$ corresponds to a greater value of the function. In other words, $f$ is increasing if when $x$ increases, $f(x)$ increases and if by decreasing $x, f(x)$ decreases.

Definition 3: A function is increasing in the interval $(a, b)$, if $f^{\prime}(x)>0$ for all $x \in(a, b)$.

Definition 4: It is said that a function $y=f(x)$ is increasing for $x=a$ if a neighborhood of $a$ verifies that: If $x>a$ then $f(x)>f(a)$ and if $x<a$ then $f(x)<f(a)$. It is said that a function $y=f(x)$ is increasing in an interval if it is increasing in all values of that interval.

The definition of a decreasing function is formulated in an analog way.

In general terms, we can say that Definition 1 matches with the one given by Osgood (1912). Let us note that definition 1 is based on the idea of function as an application or transformation between two sets; therefore, the properties of variation are properties of the applications between two sets of ordered sets. We have said before that the conception underlying this definition is that the order is preserved when the function is increasing, and is inverted when the function is decreasing. This definition, with some variations, is found in the most common textbooks in the first years of college in our country (Apostol, 1967; Arteaga \& Espinoza 2014; Leithold, 1992; Ortiz, 2009; Ortiz, et al., 2011; Stewart, 2007; Swokowski, 1982; Valdés, 1983).

Definition 2 is aligned with the definition given by Ampère in 1824, even when it is not a proper definition but an informal expression or explanation of the idea of increase or decrease according to the intuitive idea of dynamic variation of functions mentioned in the previous paragraphs. This definition is presented in the textbooks Ayres (1971), Ayres and Mendelson (2001), Contreras (2014), Cuéllar (2007), Garza (2015), Granville (2007) and Ibañez and García (2007).

Definition 3 introduces strong restrictions to the field of application of functions that can be considered as increasing or decreasing. The first of these restrictions refers to the condition that functions should be defined at an interval, while definition 1 defines functions in an arbitrary numerical set S. The other restriction, stronger than the first one, is the requirement of differentiability in the interior points of the interval in the domain. More than a definition, it is the condition established in the theorem that connects the sign of the derivative with the sense of variation of the function. We find this definition in the textbooks of Aguilar et al. (2010), Arteaga and Espinoza, (2014), Garza (2015) and Silva (2014).

Definition 4 considers first the increase of a function in a punctual way and then used this to define the global notion of increase introducing a universal quantifier for the points of an interval. It can be observed in this definition that being defined at an interval is an absolutely necessary condition and it is not possible to weaken it by replacing the interval with an arbitrary set, because it is possible to find non-increasing functions, from the intuitive point of view or from definition 1, that satisfy definition 4 when the domain is a disconnected set, like in the case of the union of two disconnected sets. It is possible to prove that if a function is increasing in an arbitrary set in the sense of definition 1 then it is also increasing in the sense of definition 4 , but the reciprocal claim is not satisfied (counterexample: the function $f(x)=-\frac{1}{x}$ defined in $\mathbb{R} \backslash\{0\}$ ). However in a connected domain, both definitions are equivalent. This definition was only found in Sántalo and Carbonell (2011).

The former discussion is summarized in Table 1. The first column identifies the definitions found in the textbooks and the second column identifies their relationship with other definitions identified in the epistemological analysis. 
Table 1. Comparative analysis of the definitions DEFINITIONS

\begin{tabular}{ll}
\hline Found in textbooks & $\begin{array}{l}\text { Identified in the } \\
\text { epistemological analysis }\end{array}$ \\
\hline
\end{tabular}

\section{Comments}

The two definitions establish the same conditions.

An important element rests on the fact that the proposal of Osgood (1912) is the result of the analysis of the contributions of Fourier, Ampère, Lagrange and Cauchy; each of these mathematicians made contributions to the definition essentially from a geometrical and algebraic approach. However, the definition in the textbook does not have this background,

Definition: A function is namely, a process of construction or reconstruction where the

Definition 1: A named monotonous if it has the problems that make the establishment of rigorous conditions for function $f$ is increasing following behavior: Let $x_{1}$ and increasing or decreasing functions are identified. in a set $S$, if for any two $x_{2}$ be two arbitrary points in the According to Chorlay (2010), even when only one quantifier points $x_{1}$ and $x_{2}$ of $S, \quad$ domain of definition such that appears, there is a double hidden quantification in the $x_{1}<x_{2}$ implies that $\quad x_{1}<x_{2}$. Then, without exceptions, definition (for any element $x_{1}$ of $S$ and any element $x_{2}$ of $S$ ) that $f\left(x_{1}\right) \leq f\left(x_{2}\right) . \quad$ it should always be $f\left(x_{1}\right) \leq$ $f\left(x_{2}\right)$, or always be $f\left(x_{1}\right) \geq$ $f\left(x_{2}\right),($ Osgood, 1912). is undoubtedly an important obstacle for students' comprehension because formulations with double universal quantification followed by an order hypothesis (as in this case) lead to difficulties due to the poor cognitive integration of the definition in the long term and to the smooth integration of the conceptual image from the beginning. Even when this double quantification is correct from a technical point of view, it is not correct from a cognitive and epistemological point of view (in which the differences between the local and global properties are emphasized).

\begin{tabular}{ll}
\hline $\begin{array}{l}\text { Definition 2: A } \\
\text { function } f \text { is said to be } \\
\text { increasing, when a }\end{array}$ & $\begin{array}{l}\text { Definition: It is said that a } \\
\text { continuous function is } \\
\text { increasing at an interval } \\
\text { greater value of the }\end{array}$ \\
$\begin{array}{ll}\text { argument } x & \text { independent variable if it } \\
\text { corresponds to a } & \text { increases for larger values of } \\
\text { greater value of the } & \text { this variable and, } \\
\text { function. In other } & \text { consequently, it decreases for } \\
\text { words, } f \text { is increasing if } & \text { smaller values of the same } \\
\text { increasing } x \text {, increases } & \text { variable; it is said that the } \\
f(x) \text { and if by } & \text { function is decreasing if its } \\
\text { decreasing } x \text {, decreases } & \text { values are decreasing as long } \\
f(x) \text { The definition of a as the independent variable } \\
\text { decreasing function is } & \text { increases to the extent that } \\
\text { formulated in an analog such variable decreases }\end{array}$
\end{tabular}
way.

\section{Definition 3. A}

function is increasing

in the interval $(a, b)$, if $f^{\prime}(x)>0$ for all $x \in(a$, b).

Definition 4. It is said

that a function $y=f(x)$ is increasing for $x=a$ if a neighborhood of $a$ verifies that: If $x>a$ then $f(x)>f(a)$ and if $x<a$ then $f(x)<f(a)$. It is said that a function $y=f(x)$ is increasing at an interval if it is increasing in all values of that interval.
It is wise to highlight that the definition of Ampère is supported by the explanation of the behavior of the quotient of variations between the independent and dependent variables. Specifically, it establishes that: if $y$ and $Y$ represent the values of the function of one independent variable, corresponding to the two values $x$ and $X$ of this variable, the quotient $\frac{Y-y}{X-x}$ of the differences of the variable and its function, will always be positive for increasing functions, and negative for decreasing functions.

This definition has an implicit notion of slope (according to the actual theory); however, this idea promotes the comprehension of the behavior of a function in each of the points of the definition. The definition in the textbook only addresses the implication but hides the condition that made the formulation possible.

In this case, the epistemological analysis identified that the definition established in the textbooks is formulated as a theorem. This definition excludes the field of functions that are not derivable but where it is possible to identify if they are increasing or decreasing functions.

This definition in the textbooks differs from the others in that it defines if a function is increasing or decreasing at a single point and then extends the definition to the points of an interval, and finally, in the whole interval. It can be observed in this definition that being defined at an interval is an absolutely necessary condition and is not possible to weaken it by replacing the interval with an arbitrary set. It is possible to show that, in an arbitrary set, if a function is increasing (in the sense of definition 1) then it is locally increasing (in the sense of definition 4) but that the affirmation of the reciprocal is not satisfied. That is to say, there are functions defined in an arbitrary set that are locally increasing but not globally increasing. However, in a connected domain, both definitions are equivalent. The authors of this definition see the need to explain that "a function is increasing if by increasing $x$ then $y$ also increases ". 


\section{ANALYSIS OF THE MAIN THEOREMS OF THE SENSE OF VARIATION OF A FUNCTION IN TEXTBOOKS}

We will present some notes about the only textbooks that make explicit the theorem that links the sign of the derivative with the sense of variation of a function and are primarily used in the first years of college. Apostol (1967), Ayres (1971), Ayres and Mendelson (2001), Leithold (1992), Piskunov (2008), Swokowski (1982) and Valdés (1983) show classic demonstrations; that is to say, the proof is based on the theorem of finite increments. Furthermore, they show graphical explanations to make evident that the slope of the tangent lines that represent the function at the points in the intervals where the function is increasing is positive and associate it immediately with the derivative of the function. On the other hand, the books of Contreras (2014), Ortiz (2007), Ortiz et al. (2011) and Stewart (2007) show the graphical explanation mentioned before without giving a demonstration.

The books of Ayres (1971) and Granville (2007) enunciate the theorem in only one sense. However, they both present identical demonstrations (except for differences in notation) to the one in Cauchy (1823). We have already mentioned in the epistemological study that this proof has a misstep. We referred to the step where the positivity of $f^{\prime}$ in a point $x_{0}$ implies the growth of the function $f$ in a neighborhood of $x_{0}$. The year 2001 edition of the book of Ayres, written in collaboration with Mendelson, corrects this mistake and shows the classic demonstration using the theorem of finite increments.

\section{ANALYSIS OF THE EFFECTIVE PROCEDURES}

With regard to the processes found in the analyzed textbooks, three steps are used to determine the sense of variation of the functions: (1) obtain the derivative $f^{\prime}(x)$ of the function, (2) obtain the critical values and (3) determine the sign of the derivative $f^{\prime}$ of the function $f$. It is in the third step where variations are observed because there were at least two procedures in the analyzed texts. The first procedure corresponds to the solution made by algebraic methods using inequalities, it was found in Aguilar et al. (2010). The second procedure goes as follows: after the points where the derivative is zero are determined, one smaller value and one greater value than the root (probative value) are chosen for each of these points. These values are substituted in the analytical expression of the derivative and the signs of these values are observed.

We point out that the study of the sign of the derivative in the second procedure was only made for integer roots, consecutive integer values and focused their attention on the use of a "probative number", "chosen value", "smaller value" or "bigger value" inside the interval of the domain; this value substitutes the independent variable in the derivative and the sign of the result is considered so that the function is increasing if $f^{\prime}(x)>0$ and decreasing if $f^{\prime}(x)<0$.

\section{PRODUCTIONS OF THE STUDENTS}

Several activities were conducted in the search for mathematical elements associated with the topic of analysis of functions in the students. These instruments were applied to fourteen students in their first year of the Bachelor's in Mathematics at UAG; they had already studied a differential calculus course as part of their pre-college curriculum. There were two main goals in these activities: (1) explore their prevailing mathematical elements and concepts about the study of the analysis of functions, even after their calculus course and (2) explore their strategies to solve these questions.

Results from the first objective proposed, obtained from the direct questions to the students and their written productions, suggest that they use deeply grounded mathematical elements studied in previous levels instead of explicitly using the definitions when applying the essence of "preserving order" in the concept of increasing/decreasing function. More precisely, not one of them managed to define the concepts of increasing or decreasing functions when they were asked to do so; they used expressions such as "if the graph goes up, the function is increasing; and if it goes down, it is decreasing". When they were shown the graph of a parabola, a piecewise monotone function which is increasing at some intervals and decreasing at others, the students answered "if we placed ourselves in the vertex of the parabola and walked to the left, the function is increasing, and if we walked to the right, the function is also increasing".

When they were asked later on to order the numbers $f(-1)$ and $f(1)$ given that $f$ is an increasing function, they claim that $f(-1)$ should be smaller than $f(1)$ because -1 is a negative number; it was really complicated for them to compare the images of a function only with the information of monotony. 


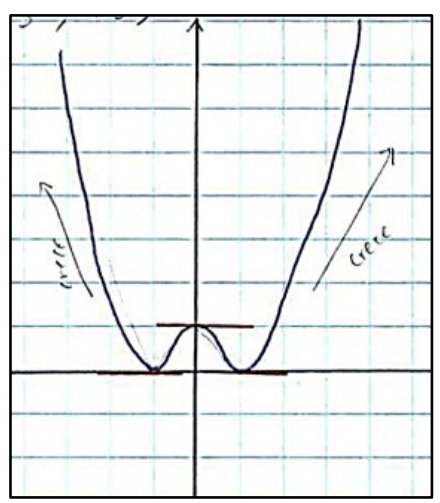

Figure 2. Alternative conception of increasing function obtained from a student

The instrument used made to respond to both objectives, had only one activity with a polynomial function of the form $f(x)=x^{4}-2 x^{2}+1$; students were asked to obtain: the intervals where the function is increasing or decreasing and relative or global maximums and minimums.

On the procedural level, these difficulties are present in the analysis of functions. One of the alternative conceptions expressed by Valero (2003), namely a function is increasing if its graph goes up, with no coordination among the changes in the abscissae and the changes in the ordinates; a function is decreasing if its graph goes down, emerges in the students that did not get an acceptable result when they established that if the graph goes up towards either side, then the function is increasing (Figure 2). An analogous procedure is assumed for a decreasing function.

It can be noted that these results are part of the problem related to the concept of increasing/decreasing function; this problem could come from the fact that pre-college teachers do not use definitions in class so students will only form intuitive ideas, but also from the diverse characterizations of the definitions found in the textbooks or because names can sometimes induce mistakes, in this case because the intuitive notion we all have of an increasing function is that the graph is ascending.

With regard to the strategies for solving obtained in the written document, we found that all students applied a "standard" procedure documented in the analysis of textbooks: (1) deriving the function, (2) equating it to zero, (3) analysis of the sign, (4) applying the criterion of the first derivative. We identified two significant procedures in the third step obtained from four students that attained an acceptable result. A first process, used by two students, is the use of inequalities and locating these points in the sketch of the graph. A second process is the use of a "probative number"involving the application of a table with a not-founded method whose procedure consists of the determination of the critical points, the establishment of intervals of domain of the function for each of them, then considering a "probative number", "choosing a value", "smaller number" or "bigger number" inside the interval and substituting it in the independent variable and evaluating the derivative. The sign of the result is obtained: if the sign of $f^{\prime}(x)>0$ then it is increasing, and if the sign of $f^{\prime}(x)<0$ then it is decreasing. This second strategy is found in the characterization presented in some textbooks during the analysis of the sense of variation of the functions. About the rest of the productions, three students used the second procedure without getting the solutions and the rest could not finish this part, one of them because he made mistakes in the derivative.

From the application of this instrument, we observed some particularities that are important to highlight. The only examples shown in the textbooks are polynomial functions; the use of the "probative value" is not grounded and only shows examples with integer values. These particularities lead to making mistakes like the following: not being able to identify an inflection point when it appears and making changes to the quadrants in the Cartesian plane; the identification of the monotony when it changes between two integer roots; and the application of concepts during the analysis of the sign. These identified particularities are part of the intuitive ideas formed previously by the students.

About the question to obtain maximums and minimums, most of the students obtained the correct solution, with some differences. Some of them solved the problem by determining the critical points and substituting them in the function $f$ to determine the coordinates of the maximum and minimum points; then the conceptions found by Valero (2003) appeared again about the consideration of zeros in the function as points of 
stabilization. On the other hand, other students located the extreme points identifying them graphically. The use of the definition is not observed.

\section{CONCLUSIONS}

The historical study of the sense of variation shows that the first definitions were presented in a "narrative style" or with purely geometrical arguments. The comparison between these definitions and those posed in current textbooks gives evidence that the current presentations hide the process of reconstruction and the resources that enabled the formal exposition of the definitions and theorems about the growth or decay of a function. It was also identified that the actual definition (increasing/decreasing function) was given by Osgood in 1912.

The proofs of the properties given by Lagrange and Cauchy showed that they did not understand the notion of growth and decay of a function in the same way. The implicit conceptions of an increasing function that appear in the proofs that result in the theorem that links the sign of the derivative with the sense of variation of a function are not exactly the same, because they had different goals to achieve. Lagrange was focused on finding bounds for the remainder in the polynomial development of order $n-1$, while the intention of Cauchy was to ground his formalization works of the analysis of the notion of limit. Therefore, this was a notion that both mathematicians considered evident.

The review of the textbooks gives evidence of the small importance given to definitions and theorems; the conceptions identified in the evolution of the notion of the sense of variation were also found in some of these textbooks. It even gives evidence of the lack of seriousness in the presentation of the theorem that links the sign of $f^{\prime}$ with the sense of variation of a function $f$, because it is presented in a narrative style in some texts (Ayres, 1967; Granville, 2017). These authors presented a very similar demonstration to the one shown by Cauchy that, as said before, contains some mistakes. A consequence of this problem is that the processes to analyze the sense of variation of functions are presented as an algorithmic sequence of steps without a profound analysis, making more difficult the appropriation of these definitions and theorems, even in a long term. As documented in the study, conducted with students to explore the concepts associated with the analysis of variation of functions, the students followed the definitions and theorems found in the textbooks; some of them answered intuitively without mature and solid arguments to handle the conceptual level required for this type of study.

These findings in the epistemological, didactical and cognitive study will be considered for the design of a system of activities in a didactical engineering that promotes the transition between the dynamical and static work related to the concepts of increasing and decreasing functions as part of the treatment of the sense of variation of a function.

\section{Disclosure statement}

No potential conflict of interest was reported by the authors.

\section{Notes on contributors}

Noé Oswaldo Cabañas-Ramírez - Autonomous University of Guerrero, Mexico.

Edgardo Locia-Espinoza - Autonomous University of Guerrero, Mexico.

Armando Morales-Carballo - Autonomous University of Guerrero, Mexico.

\section{REFERENCES}

Aguilar, A., Bravo, F., Gallegos, H., Cerón, M., \& Reyes, R., (2010). Cálculo Diferencial. México: Progreso.

Ampère, A. M. (1824). Précis des leçons sur le calcul différentiel et le calcul intégral, CRH cours: A3a 174, Palaiseau, Archives de l'École polytechnique. P. 12. https://doi.org/10.1017/cbo9780511702624.003

Apóstol, T. (1984). Calculus. México: Reverté.

Artega, S., \& Espinoza, J. (2014). Cálculo. México: Fondo de cultura económica.

Artigue, M. (1995). Ingeniería Didáctica. In M. Artigue, R. Douady, I Moreno, \& P. Gómez (Eds.) Ingeniería Didáctica en Educación Matemática (pp. 33-59). Bogotá, Colombia: Grupo Editorial Iberoamérica. https://doi.org/10.24844/em3002.01 
Ayres, F. (1967). Cálculo diferencial e integral. México: Mc Graw Hill.

Ayres, F., \& Mendelson, E. (2001). Cálculo. México: Mc Graw Hill.

Brousseau, G. (1978). "La cours a 20". In Theorie des situations didactiques (1998) La Pensee Sauvage, pp. 2443. In Etude locale des processus d'acquisition en situation scolaire, Etude sur l'enseignement elementaire (Cuaderno 18,7-21). Bordeaux, IREM y Universidad de Bordeaux 1. https://doi.org/10.7202/012669ar

Castillo, M. (2009). Un estudio de concepciones del concepto de función en estudiantes de ingeniería. Acta Latinoamericana de Matemática Educativa, 22, 419-427.

Cauchy, A. (1823). Resumé des lecons données à l'École Royale Polytechnique sur le calcul infinitésimal. 1ere partie Analyse Algebraique. Paris, Francia: L'Imprimerie Royale, Debure frères, Libraires du Roi et de la Bibliothèque du Roi. https://doi.org/10.1017/cbo9780511702624.003

Chorlay, R. (2007). La multiplicité des points de vue en Analyse elementaire comme construit historique. In E. Barbin \& D. Bénard (Eds). Histoire et enseignement des mathématiques: erreurs, rigueurs, raisonnements, Lyon: INRP. 203-227.

Chorlay, R. (2010). From historical analysis to classroom work: function variation and long-term development of functional thinking. CERME6. Lyon: INRP. 2396-2405.

Chorlay, R. (2014). Signe de f' et variations de f: la fabrique d'une chaine déductive longue. Petit x, 94, 27-48.

Contreras, S. (2014). Cálculo Diferencial. México: Fondo de cultura económica.

Cuéllar, J. (2007). Matemáticas V. Cálculo Diferencial. México: Mc Graw Hill.

Cuevas, B., Sánchez, I. \& Aparicio, A. (2012). Cálculo. México: Gafra.

Cuevas, C., \& Delgado, M. (2016). ¿Por qué el concepto de función genera dificultad en el estudiante? ReCalc, 7, 108-119.

Delgado, M. (2013). Un problema con la concepción de la continuidad de una función. El Cálculo y su Enseñanza, 4, 27-44.

Díaz, M. (2009). Conocimientos de los profesores preuniversitarios de Cálculo acerca del significado y las interpretaciones de la derivada. El Cálculo y su Enseñanza, 1, 75-90.

Engler, A., Vrancken, S., Gregorini, M., Müller, D., Hecklein, M., \& Henzenn, N. (2008). Estudio del comportamiento de la función a partir de la derivada. Análisis de una secuencia didáctica. Acta Latinoamericana de Matemática Educativa, 21, 466-476. https://doi.org/10.18845/rdmei.v15i1.1992

Euler, L. (1755). Institutiones calculi differentialis. Saint Petersburg: Academiae Imperialis Scientiarum Petropolitanae.

García, O., \& Morales, L. (2013). Ideas para enseñar: El Contraejemplo como Recurso Didáctico en la Enseñanza del Cálculo. Revista Iberoamericana de Educación Matemática, 35, 161-175. https://doi.org/10.7203/eari.9.11473

Garza, B. (2015). Cálculo diferencial. México: Pearson

Granville, W. A. (2007). Cálculo diferencial e integral. México: Limusa

Hernández, J., Locia, E., Morales, A., \& Sigarreta, J. (2019). El contraejemplo en la elaboración de la definición de función convexa por estudiantes universitarios. Información Tecnológica, 30(1). https://doi.org/10.4067/s0718-07642019000100185

Ibañez, P., \& García, G. (2007). Matemáticas V. Cálculo Diferencial. México: Cosegrat.

Klymchuk, S. (2012). Counterexamples in calculus. Mathematics teaching-research journal, 5(4), 1-30.

Lagrange, L. (1797). Théorie des fonctions analytiques contenant les principes du calcul différentiel dégages de toute considération d'infiniment petits ou de'évanouissans, de limites ou de fluxions et réduits à l'analyse algébrique des quantités finies. En el $9^{\circ}$ cuaderno del Journal de l'École Polytecnique. Paris: République. https://doi.org/10.1017/cbo9780511702730.024

Lakatos, I. (1976). Proofs and Refutations: The Logical of Mathematical Discovery. Cambridge: Cambridge University Press.

Leithold, L. (1992). El cálculo con Geometría Analítica. México: Harla.

Morales, A., Locia, E., Ramírez, M., Sigarreta, J., \& Mederos, O. (2018). The Theoretical didactic approach to the counterexample in mathematics. International Journal of Research in Education Methodology, 9, 1510-1517. https://doi.org/10.24297/ijrem.v9i1.8013

Ortiz, F. (2009). Cálculo Diferencial. México: Patria. 
Ortiz, F., Ortiz, F., \& Ortiz, F. (2011). Cálculo diferencial. México: Patria.

Osgood, W. F. (1912). Lehrbuch der Funktionentheorie. Berlín, Alemania: B. G. Teubner.

Pineda, C. (2013). Una propuesta didáctica para la enseñanza del concepto de la derivada en el último grado de educación secundaria. (Tesis de Maestría). Universidad Nacional de Colombia. Bogotá, Colombia. https://doi.org/10.29375/21457190.2980

Piskunov, N. (2018). Cálculo diferencial e integral. México: Limusa.

Renaud, H. (2017). La fabrication d'un enseignement de l'analyse pour l'enseignement secondaire en France au XIXe siècle: acteurs, institutions, programmes et manuels. (Tesis Doctoral). Universidad de Nantes. Francia

Reséndiz, E. (2006). La variación en las explicaciones de los profesores en situación escolar. Revista Latinoamericana de Investigación en Matemática Educativa, 9(3), 435-458. https://doi.org/10.12802/relime.13.1933

Rey Cabrera, M. (2016). Propuesta didáctica para la formación del profesorado: el caso de la derivada como herramienta de modelización matemática. (Tesis de Maestría). Cinvestav, México. https://doi.org/10.30827/profesorado.v22i2.7735

Rolle, M. (1691). Démonstration d'une méthode pour résoudre les égalités de tous les degrés, suivie de deux autres méthodes, dont la première donne les moyens de résoudre ces mêmes égalités par la géométrie, et la seconde pur résoudre plusiers questions de Diophante qui n’ont point été résoluës. París. https://doi.org/10.5802/afst.170

Rubí, G., Moreno, M., Pou, S., \& Jordán, A. (2010). Problemática persistente en el aprendizaje de Cálculo: Caso de la Facultad de Ciencias, UABC. El Cálculo y su enseñanza, 2, 1-10. https://doi.org/10.15517/revedu.v37i1.10627

Ruiz, E., Hernández, J., \& Gutiérrez, J. (2015). Aplicaciones en dispositivos móviles enfocadas al estudio de conceptos de cálculo. El cálculo y su enseñanza, 6, 123-144.

Russo, C. (2016). Diseño de una secuencia didáctica para el estudio del concepto de función utilizando software de geometría dinámica (Master's Thesis). Cinvestav, México.

Salinas, P., \& Alanís, J. A. (2009). Hacia un nuevo paradigma en la enseñanza del cálculo dentro de una institución educativa. Revista Latinoamericana de Investigación En Matemática Educativa. 12(3), 355382. https://doi.org/10.12802/relime13.1910

Sánchez-Matamoros, G., García, M. \& Llinares, S. (2008). La comprensión de la derivada como objeto de investigación en didáctica de la matemática. Revista Latinoamericana de Investigación en Matemática Educativa, 11(2), 267-296. https://doi.org/10.12802/relime.17.2024

Sántalo, M., \& Carbonell, V. (2007). Cálculo diferencial. México: Diana.

Silva, J. (2014). Cálculo Diferencial. México: Anglo.

Stewart, J. (2007). Cálculo Diferencial e Integral. EEUU: Thomson.

Suárez, C. O. (2011). Orígenes y evolución del Teorema de Rolle. Épsilon. Revista de Educación Matemática, 28(77), 39-50.

Suso, C., \& Velasco, M. V. (2013). Sobre la génesis y evolución del Teorema de Rolle. Épsilon. Revista de Educación Matemática, 30(83), 49-66.

Swokowski, E. (1982). Cálculo con Geometría Analítica. EEUU: Wadsworth Internacional Iberoamérica.

Valdés, C. (1983). Análisis matemático, Tomo II. Cuba: Pueblo y Educación.

Valero, S. (2003). Estabilidad y cambio de concepciones alternativas acerca del análisis de funciones en situación escolar. (Tesis Doctoral). CICATA-IPN. México.

Zazkis, R., \& Chernoff, E. (2008). What makes a counterexample exemplary? Educational Studies in Mathematics, 68, 195-208. https://doi.org/10.1007/s10649-007-9110-4

Zúñiga, M. (2009). Un estudio acerca de la construcción del concepto de función, visualización. en alumnos de un curso de cálculo I (Master's Thesis) UPN. Tegucigalpa, Honduras. https://doi.org/10.17013/risti.16.116 